\title{
O Regulamento InTERnACional da SAÚdE ${ }^{(*)}$
}

Mónica Bolis ${ }^{(\star \star)}$

\section{RESUMO}

O artigo situa o regulamento internacional da saúde em um contexto atual sobre a crescente globalização, demonstrando que a saúde, indiretamente, tem muito a beneficiar-se com as alianças comerciais entre os Estados, conseqüência do reconhecimento de que a saúde tem importância expressiva sobre a economia. Daí a importância de um regulamento com aplicação supranacional que alcance todos os envolvidos.

\section{Descritores}

Regulamento; Saúde; Medicamentos; Globalização.

\section{ABSTRACT}

The article situates the law international of health in a context he acts and crescent globalization, demonstrating that of the health, indirectly, does have a lot the one benefitt with the commercial alliances amidst the estates consequent of the acknowledgement what health does have amount expressive on the economy. Hence the amount by one law with application supranacional that to purview of all involved.

\section{Key-words}

Regulation; Heath; Drugs; Globalization.

(*) Para ser apresentado en el V Seminario Internacional de Derecho Sanitario. São Paulo, Brasil, 37 de outubro de 1999.

$\left.{ }^{\star \star *}\right)$ Asesora Regional en Legislación de Salud, Programa de Políticas Públicas y Salud, División de Salud y Desarrollo Humano, Organización Panamericana de la Salud, Organización Mundial de la Salud (OPS/OMS). E-mail: bolismo@ paho.org — Entrada: 5.3.2003. Aprovado: 23.6.2003. 


\section{INTRODUÇÃO}

O assunto que nos ocupa nesta ocasião é extremamente favorável para a região das Américas em conseqüência de dois acontecimentos que parecem estar relacionados. Em primeiro lugar, exatamente no mês de outubro, nossa região se prepara para comemorar os 75 anos do Código Sanitário Panamericano como primeiro instrumento estabelecido por meio de um tratado para o Regulamento da Saúde e do Comércio Continentais. Este aniversário não ocorre em um vazio, mas se insere num contexto muito mais amplo de uma era que se caracteriza pela busca de novas alianças comerciais, em que a saúde ocupa, como há 75 anos, um lugar fundamental.

Considerando esses dois fatores, o objetivo desta apresentação é analisar os novos mecanismos do regulamento da saúde, no âmbito da "supranacionalidade" americana, sobre o comércio internacional de bens, produtos e serviços da saúde. Este fenômeno destaca a necessidade de compatibilizar a incorporação dos países em processos amplos de desenvolvimento, com a importância de garantir a qualidade e a inocuidade dos produtos que participam desse intercâmbio, para assegurar que os processos de integração regional resultem em benefícios às populações de nossa região.

\section{GLOBALIZAÇÃO E SAÚDE NA REGIÃO DAS AMÉRICAS. NOVOS MECANISMOS DO REGULAMENTO INTERNACIONAL}

A região das Américas encontra-se imersa na definição de novas pautas para as relações entre seus Estados, fundamentadas em um modelo que privilegie a globalização econômica e a integração regional. A globalização econômica presente nos processos de integração apresenta uma cena diferente do passado. Agora, a competitividade substitui o protecionismo, e as economias emergentes buscam situar-se na matriz competitiva internacional, transformando-se em centros de atração para o investimento estrangeiro direto, e em correntes dinâmicas dos bens e serviços ${ }^{(1)}$.

O fenômeno da globalização começou a deixar suas trilhas no início desta década, ao reimplementar modelos de integração tradicionais, como o antigo Pacto Andino e o Sistema de Integração Centro-Americano (SICA), formularam-se novos espaços de intercâmbio como o Mercado Comum do Sul (MERCOSUL) e o Tratado de Livre Comércio de América do Norte (TLC), e ampliaram-se as dimensões da estrutura regional por meio da criação da

(1) Abreu, Sergio. "La conformación de las comunidades supranacionales y el derecho internacional". In Hacia la definición de una agenda para salud en los procesos de globalización económica. Serie Informes Técnicos N. 67. Programa de Políticas Públicas y Salud. División de Salud y Desarrollo Humano. OSP/OMS, 1998. 
área de comércio livre de Américas (ALCA) a ser alcançada em 2004. A Associação dos Estados do Caribe (AEC) também faz eco à globalização ao enunciar, entre os objetivos de sua criação, a integração econômica, incluindo o liberalização do comércio.

A reimplantação da dinâmica regional, por meio da criação de estruturas mais ágeis para o intercâmbio, encontram suporte na criação da Organização Mundial do Comércio (OMC) que estabelece um plano de ação comum rumo ao desenvolvimento de um comércio cada vez mais livre e sustentado, com obrigações correlatas para os Estados.

A globalização se encontra intrinsecamente ligada à saúde por meio da conjugação de aspectos negativos e de desafios. A área escura da globalização está associada ao que se poderia denominar de "efeitos residuais" surgidos da necessidade que os países se conformem com as receitas econômicas internacionais. Surgem aqui as condições ligadas à inserção de um poderoso setor privado, à deterioração das condições do trabalho, ao aumento dos riscos ambientais e a debilitação da estrutura econômica dos países menos desenvolvidos. Somam-se a estas, as condições resultantes da internacionalização dos riscos, por meio das pandemias de HIV/AIDS e do comércio internacional de drogas e tabaco.

Sem reduzir a importância dos riscos, a globalização cria uma dinâmica que pode beneficiar saúde. Esta dimensão baseia-se no reconhecimento, cada vez mais apurado, de que a saúde representa um segmento importante na economia. Neste sentido, o setor da saúde transforma-se em uma contrapartida da importância para a formulação de políticas comuns e a criação de estratégias internacionais de controle, credibilidade, certificação e homologação de normas para assegurar a qualidade e garantir o acesso a um mercado cada vez mais competitivo. Estas características se fazem notar em particular nos direitos internacionais, já que em muitos casos se evidencia a existência de legislações dispersas, anacrônicas e carentes de linha doutrinária definida, fenômeno que cria uma defasagem entre a intenção do texto legal e sua real aplicação.

Entre as áreas que o setor de saúde pode contribuir, são os seguintes ${ }^{(2)}$ :

- Medicamentos: Mediante a definição de práticas comumente adotadas que regem o registro e a comercialização dos produtos farmacêuticos, assim como a formulação de orientações a serem incorporadas nas normas sobre patentes, necessárias para cumprir os requisitos estabelecidos pelo Acordo sobre Aspectos Comerciais de Propriedade Intelectual (TRIPS).

(2) Programa de Políticas Públicas y Salud. División de Salud y Desarrollo Humano. OPS/OMS. La salud en las agendas de globalizacón económica. Documento para discusión presentado al Gabinete. Agosto, 1997. 
- Alimentos: Mediante a formulação de normas adequadas em um sistema em que o Codex Alimentarius é a única norma internacional aceita, embora pareça ser a "parte traseira" em comparação com os padrões nacionais dos países mais desenvolvidos.

- Serviços de saúde: Mediante a formulação de normas internacionalmente aceitas para a credibilidade de serviços e certificação de provedores de serviços para assegurar a qualidade e o acesso aos mesmos.

- Seguro de saúde: Mediante a definição de normas para esquemas de seguros de saúde que sejam equivalentes e que facilitem a cobertura transnacional.

- Tecnologia médica: Mediante a definição de normas e nomenclaturas para a produção de tecnologias para tratamento e reabilitação, equipamentos médico, dental e hospitalares.

- Equipamentos e serviços de telecomunicação e informação: Mediante a entrega de cooperação para definir tecnologia apropriada para meIhorar a qualidade e o acesso, controlar os custos e normalizar o dados necessários para a operação e manejo dos serviços de atenção.

- Segurança do trabalho, ambiental e da diversidade biológica: Mediante a definição de normas para a proteção do ambiente e a garantia de condiciões seguras de trabalho.

- Outros produtos de saúde: Mediante a definição de normas e nomenclaturas em campos como a biotecnologia, reagentes e insumos para diagnóstico, as vazias e os produtos imunobiológicos.

A elaboração de pautas no contexto indicado, parece obedecer a uma dinâmica que conserva os parâmetros tradicionais. Nos encontramos diante do que se denomina formação dos denominados "direitos comunitários", que procedem de entidades e comissões de integração que, com variações próprias, se encontram integrados por conselhos, comissões (econômicas e sociais), programas, convênios setoriais, secretarias e parlamentos. Isto destaca que o Regulamento Supranacional da Saúde é discutido em várias das instâncias que se mostram no quadro $n$. 1, ou em todas elas, com as respectivas conseqüências para a expedidora da decisão.

Quadro N.1

Instancias de Integración Afectando el Sector Salud en América Latina y el Caribe

\begin{tabular}{|l|l|l|}
\hline \multicolumn{1}{|c|}{ Âmbito } & \multicolumn{1}{|c|}{ Acordos Multisetoriais } & Instituições setoriais \\
\hline Global & OMC & OMS \\
\hline Regional & ALCA & OPS \\
\hline
\end{tabular}




\begin{tabular}{|l|l|l|}
\hline \multicolumn{1}{|c|}{ Âmbito } & \multicolumn{1}{|c|}{ Acordos Multisetoriais } & Instituições setoriais \\
\hline Sub-regional & $\begin{array}{l}\text { NAFTA, MCCA, CARICOM, } \\
\text { C. ANDINA, MERCOSUL }\end{array}$ & $\begin{array}{l}\mathrm{CHU}^{(3)} \mathrm{RESSCA}^{(4)}, \\
\mathrm{REMSA}^{(5)}, \mathrm{CH}^{(6)}, \\
\text { INCOSUR }^{(7)}\end{array}$ \\
\hline Bi/Multilateral & ALADI, etc. & $\begin{array}{l}\text { CUB/GUY, } \text { ASFMES }^{(8)} \\
\text { etc. }\end{array}$ \\
\hline
\end{tabular}

Fonte: Vieira, C. "Introdução". In Hacia la definición de una agenda para salud en los procesos de globalización Económica. Serie de Informes Técnicos N. 67. HDP/HDD. OPS/OMS, 1998.

Soma-se à condição anterior, o fato de os processos de globalização serem controlados principalmente pelos ministérios de indústria, comércio e relações exteriores. A participação dos ministérios da saúde é escassa ou nula, o que constitui uma série de riscos de importância capazes de afetar não somente a qualidade, como também as condições de acesso aos bens e serviços de saúde ${ }^{(9)}$.

A homologação das normas para permitir o intercâmbio, por exemplo, é feita em muitos casos à margem da institucionalidade setorial da saúde. Novamente, as brechas na qualidade e no acesso são estimuladas com a conformação de uma "jurisprudência de fato" surgida da necessidade de resolver os conflitos que ocorrem durante as negociações que envolvem governos, empresas e consumidores e requerem soluções urgentes ${ }^{(10)}$. Por outro lado, no nível do setor privado, estão se gerenciando alianças que, sobretudo no aspecto do financiamento da prestação transnacional de serviços, não são devidamente reguladas, criando precedentes capazes de engrossar a mencionada "jurisprudência de fato". Por exemplo, em 1996 um acordo entre o Centro Assistencial do Sindicato Médico do Uruguai (SMU), as Cooperativas Médicas da Argentina (FEMEA) e o Brasil (UNIMED) criaram o "Cartão do MERCOSUL", que permite o acesso à prestação de saúde aos portadores ${ }^{(11)}$.

(3) Convenio Hipólito Unanue.

(4) Reunión del Sector Salud de Centroamérica.

(5) Reunión de Ministros de Salud del Area Andina.

(6) Caribbean Health Initiative.

(7) Iniciativa de Salud del Cono Sur.

(8) Associación de Salud de la Frontera México-Estados Unidos.

(9) Bolis, Mónica. Oportunidades de cooperación técnica en salud en el marco de la nueva dinámica integracionista: Comunidad Andina y MERCOSUL. Documento de análisis presentado en la Reunión Subregional de PWRs, Directores de Centros y Administradores. Santiago, Chile. Abril, 1997. OPS/ OMS.

(10) Programa de Políticas Púbicas y Salud. División de Salud y Desarrollo Humano. La Organización Panamericana de la Salud y la Construcción del Area de Libre Comercio de las Américas. Documento Priliminar para Discusión. Abril, 1997.

(11) Vieira, C., Bolis, M., Gordillo, A. Informe de Viaje. Montevideo, Uruguay. Noviembre, 1996. Citado en ibid. 
O panorama se complica devido àquelas normas definidas comumente em níveis supranacionais devendo ingressar no direito interno dos Estados por meio dos atos normativos correspondentes. Também neste caso, notam-se deficiências, já que os mecanismos de assimilação da norma internacional não atuam com a celeridade que se requer. Embora se perceba uma mudança na estruturação dos entes de integração sobre as plataformas para a discussão e tratamento de temas de saúde, como no caso do MERCOSUL, em que se criou o Subgrupo de Trabalho n. 11, específico para a saúde e a incorporação do Convênio Hipólito Ananue ao Sistema de Integração Andino. O processo ainda é lento.

Diante de um fenômeno irreversível como o da globalização, faz-se necessário buscar novos mecanismos para garantir que todos os envolvidos estejam representados nas negociações.

E que este processo seja suficientemente ágil e consistente para fortalecer a seguridade nas relações entre os Estados em relação à saúde. Várias são as soluções propostas. Em primeiro lugar, os organismos internacionais de saúde como a OSP e a OMS poderiam assumir um rol de importância na definição de pautas tanto no que se refere a regulação quanto a definição de novas políticas para a supranacionalidade. Estas instituições são organismos internacionais e não supranacionais. Isso destaca que muitas de suas decisões não sejam automaticamente obrigatórias a todos os Países Membros, que conservam autonomia a este respeito. Sem contestar a sua devida legitimidade, mas na realidade sua capacidade para obter consensos se converte em fator de peso na nova dinâmica. Outra alternativa estaria na criação de um comitê de países que atuem em nome dos países americanos, ou em uma nova instituição que se crie para esse fim, à maneira da Comunidade Européia. São estas as alternativas.

\section{CONCLUSÕES E RECOMENDAÇÕES}

A exposição anterior leva a considerar uma nova realidade no âmbito da regulação internacional da saúde, em que os Estados Nacionais transfiram suas funções normativas às instâncias criadas para permitir o funcionamento do instrumento próprio para a integração subregional e regional. Isto gera uma dupla instabilidade. Por um lado, não existe uma definição clara de competências entre os distintos blocos no tratamento de aspectos comuns, sobretudo no que se refere aos produtos de maior intercâmbio como são, por exemplo, os alimentos e os medicamentos. Por outro lado, uma vez aprovada pelos corpos supranacionais, a norma deve ser assumida em nível nacional, processo que na maioria dos casos parece ser lento.

A solução parece estar na necessidade de revisar os acordos atualmente existentes, de maneira tal a distribuir uma conectividade que permita 
que uma vez discutido um tema em algum dos elos e acordadas as pautas correspondentes, estas tenham validez ou pelo menos sirvam de precedente obrigatório para as discussões em outros blocos. Assim mesmo, deve agilizar-se o processo de incorporação das normas comunitárias no nível dos Estados Nacionais, criando-se a obrigação para que estes de assimilarem-se ao Direito Nacional no tempo mais curto possível. 